\title{
Long-Term Maintenance Scheduling of Smart Distribution System through a PSO-TS Algorithm
}

\author{
Jianxue Wang, Jianming Lu, Zhaohong Bie, Shutang You, and Xiaoyu Cao \\ School of Electrical Engineering, Xi'an Jiaotong University, Xian, Shaanxi 710049, China \\ Correspondence should be addressed to Jianxue Wang; jxwang@mail.xjtu.edu.cn
}

Received 21 January 2014; Revised 28 April 2014; Accepted 3 May 2014; Published 22 May 2014

Academic Editor: Hongjie Jia

Copyright ( 2014 Jianxue Wang et al. This is an open access article distributed under the Creative Commons Attribution License, which permits unrestricted use, distribution, and reproduction in any medium, provided the original work is properly cited.

\begin{abstract}
Asset management of distribution systems is an important issue for smart grid. Maintenance scheduling, as an important part of asset management, affects the reliability of distribution equipment and power supply. This research focuses on long-term distribution system maintenance scheduling aided by available operation information, which is a prominent advantage of smart grid over conventional distribution systems. In this paper, the historical and future operation information in smart grid is taken into account through a decoupled time-varying reliability model of equipment. Based on distribution system reliability assessment, a maintenance scheduling model is proposed to determine the optimal implementation time of maintenance activities to minimize distribution systems' total cost, while satisfying reliability requirements. A combined algorithm that consists of particle swarm optimization and tabu search is designed and applied to the optimization problem. Numerical result verifies that the proposed method can schedule long-term maintenance of distribution systems in smart grid economically and effectively.
\end{abstract}

\section{Introduction}

As the most complex part in power networks, distribution systems play a fundamental role and their failures result in most interruptions of power supply. Maintenance of distribution equipment can extend equipment's service life and reduce the duration of supply outage [1]. Therefore, the reliability analysis and maintenance scheduling of distribution systems have attracted wide attention [2-4]. With the development of smart grids, the operation of distribution systems is more flexible; meanwhile, advanced distribution equipment can provide more information and better controllability [5]. Under this circumstance, new asset management methods are needed to accommodate these technical innovations. As an important part of asset management, distribution system maintenance scheduling in smart grid confronts both new problems and opportunities.

Distribution equipment maintenance can be generally divided into two types: preventive maintenance (PM) and corrective maintenance $(\mathrm{CM})$. Preventive maintenance is conducted before equipment's failure and can be scheduled, whereas corrective maintenance is performed after the occurrences of failures and it has very few optional schedules. According to different scheduling principles, preventive maintenance scheduling can be divided into several types: predetermined periodic maintenance, reliabilitycentred maintenance (RCM), and risk-based maintenance (RBM) [6-8]. Conventional RCM focuses on maximizing system reliability, but it seldom considers maintenance benefits and costs. With the deregulation of electric industry, distribution maintenance scheduling should consider economic rewards and penalties from customers according to different reliability levels of power supply [3]. A good maintenance schedule should be a reasonable balance of operation cost and reliability [9]. Therefore, risk-based maintenance (RBM) [10], which formulates maintenance schedules to minimize failure probability and its consequences, is more applicable in practice and becomes the most studied maintenance scheduling method.

Some research has proposed some models and algorithms for distribution maintenance scheduling. Mixed-integer programming is applied in [4] to schedule maintenance for overhead transmission lines. References $[6,11]$ assess the impact of different distribution components and maintenance tasks on system reliability and then select critical components and maintenance tasks to make maintenance schedules. Based 
on the risk analysis of distribution components, $[9,12]$ uses ordinal optimization and dynamic programming to schedule maintenance for multiple components. Distribution maintenance with limited information of equipment's condition is studied in [13], using fuzzy theory and integer programming to maximize system reliability.

For maintenance scheduling, the foremost and fundamental task is to form the equipment reliability model and obtain equipment's failure rates. In conventional maintenance models, equipment's condition is discretized into a few states $[4,11,14,15]$, while state-transition probabilities are set to constants. However, these assumptions are sometimes oversimplified for practical use and not accurate enough to reflect the real deterioration process. In reality, the operation condition of equipment is continuously changing with time. For example, the system load is always changing with time, so it is reasonable to consider the influence of heavy loads on transformers' insulation aging. Moreover, each failure type has its own development characteristic and corresponding failure rate varying with time. In a particular period, equipment is under different stages when evaluated according to different deterioration mechanisms. Previous work rarely takes above factors into consideration in maintenance scheduling.

The equipment monitoring devices in smart grid can record the continuously changing operation data. The smart grid framework may contain the prediction of future operation scenarios and even the preestablishment of future operation plans, but this information is rarely incorporated in current models. In this paper, operation information in smart grid is used to facilitate a more reasonable maintenance schedule for distribution systems. In the proposed method, the failure rate of distribution equipment is decoupled according to different failure mechanisms. This decoupled failure rate model is used to incorporate the information reflecting the time-varying operation conditions and environments, such as heavy load and adverse weather. Based on distribution system reliability assessment, a RBM scheduling model considering varying operation conditions is proposed to minimize distribution systems' outage losses and maintenance cost over the scheduling horizon, while satisfying reliability requirements. Due to the fact that an accurate and complete method for distribution system reliability assessment is embedded in the maintenance model, it is difficult to solve this nonlinear combinational optimization problem through conventional mathematics programming methods. Therefore, a hybrid algorithm that combines particle swarm optimization (PSO) and tabu search (TS) is designed and applied to solve this optimization problem.

The remainder of this paper is organized as follows. In Section 2, equipment's reliability model considering multiple deterioration mechanisms, as well as operation conditions and maintenance activities on equipment's reliability, is analysed. The formulation of the maintenance scheduling optimization problem is given in Section 3. The details of the PSO-TS hybrid algorithm are presented in Section 4. Section 5 is a case study based on an IEEE RBTS subsystem. Conclusions are provided in Section 6.

\section{Reliability Model of Equipment}

2.1. Multiple Deterioration Mechanisms and Failure Rate Decoupling. In some reliability models of equipment [16], two discrete states are considered: the normal state and the failure state. In these models, the failure rate of equipment equals the average value of the smooth running stage of the bathtub-shaped aging curve. In some modified models $[17,18]$, equipment is considered to have several deteriorated states and a failure state during its service life, and the transition of states is represented by the discrete Markov process. However, these models are based on the assumption that the probability of each state's duration is exponentially distributed, which is sometimes not accurate enough for practical use. In smart grid, due to the increasing flexibility of distribution system operation, more adaptable and accurate reliability models for equipment are needed.

In practice, equipment in distribution systems has various deterioration mechanisms $[4,6,9]$. For example, failures of overhead transmission lines may result from wire damage, insulator aging, or mechanical damage of poles. A circuit breaker may fail due to wear in mechanical systems, aging of insulation materials, and malfunction of internal control circuits. Other equipment such as transformers, buses, and feeders also have multiple deterioration mechanisms. These deterioration mechanisms are often inherently isolated from each other and independently result in equipment's failures [4]. Therefore, equipment's failure rate can be decoupled into several independent components of failure rate according to different failure mechanisms [9]. The total failure rate of equipment is the sum of decoupled independent component failure rates as follows:

$$
\lambda_{i}(t)=\sum_{d=1}^{D} \lambda_{i}^{d}(t)
$$

where $\lambda_{i}(t)$ is the failure rate of equipment $i$ in period $t$ and $\lambda_{i}^{d}(t)$ is the failure rate of equipment $i$ 's $d$ th deterioration type in period $t . D$ is the number of deterioration mechanisms. The characteristics of each failure rate component can be described by its own failure rate curve. Each decoupled failure rate component is modelled by the Weibull function with different coefficients as follows:

$$
\lambda_{i}^{d}(t)=h_{i}^{d}\left[\left(\frac{\beta_{1, i}^{d}}{\alpha_{1, i}^{d}}\right)\left(\frac{t}{\alpha_{1, i}^{d}}\right)^{\beta_{1, i}^{d}-1}+\left(\frac{\beta_{2, i}^{d}}{\alpha_{2, i}^{d}}\right)\left(\frac{t}{\alpha_{2, i}^{d}}\right)^{\beta_{2, i}^{d}-1}\right],
$$

where $h_{i}^{d}, \alpha_{1, i}^{d}, \beta_{1, i}^{d}, \alpha_{2, i}^{d}$, and $\beta_{2, i}^{d}$ are Weibull coefficients. Based on empirical or experimental data, these parameters' values can be estimated through the least-square-fitting method [19]. Referring to [4, 9], an example of the decoupled and total failure rate curves using the Weibull function is presented in Figure 1. Apart from the Weibull function, other functions can also be used to fit the specific characteristics of different deterioration processes and different equipment when necessary. 


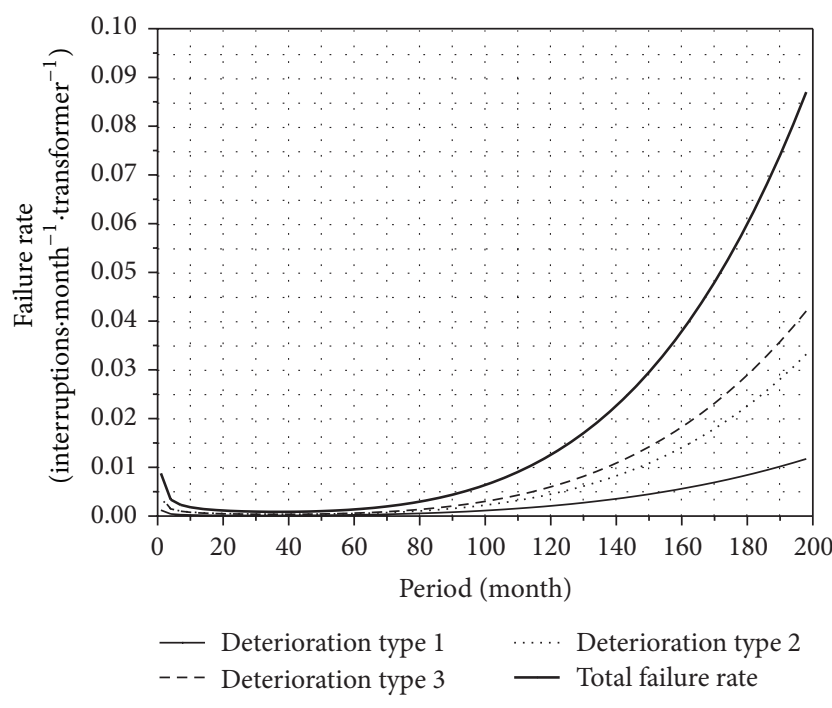

Figure 1: An example of decoupled failure rate curves.

2.2. The Impact of Operation Conditions-Heavy Load as an Example. Meters and sensors in smart grids provide much system operation information. With this information, the condition of system components can be more accurately assessed. A frequently occurred operation condition, heavy load, is analyzed here as an example.

With the growth of load demand and the aggregated load such as simultaneously charging batteries of electrical vehicles, heavy load situations are not rare in distribution systems. Overload situations can be recorded and sometimes predicted by smart grid devices. Thus, their impacts on equipment reliability can be quantified. Generally, the heavy load will accelerate certain failure processes of electrical equipment, resulting in corresponding increase in failure rate components [20]. For instance, overheat due to heavy load will accelerate the insulation aging process of transformers, thereby increasing the insulation failure rate. According to Arrhenius law [21], the insulation life loss of transformers can be obtained as follows:

$$
\Delta T_{\text {Loss }}=\int_{t_{1}}^{t_{2}} V^{\prime} d t=\int_{t_{1}}^{t_{2}} 2^{\left(\theta_{t, h}-98\right) / 6} d t,
$$

where $V^{\prime}$ denotes the relative aging rate. $\theta_{t, h}$ represents the hot spot temperature of a transformer's winding. This temperature value, which relates to transformer parameters and load values, can be calculated through the method provided in [22]. $\left(t_{1}, t_{2}\right)$ represents the interval of the heavy load period. Figure 2 shows the impact of the heavy load on the insulation failure rate. The influence of other operation conditions on equipment, such as bad weather's influences on pole and insulator damage, can also be similarly modelled through modifying (2) and (3).

2.3. The Impact of Maintenance. Maintenance tasks are often targeted at improving a certain part of equipment, such as vegetation pruning and conductor and pole refurbishment. Therefore, each maintenance activity only reduces one or

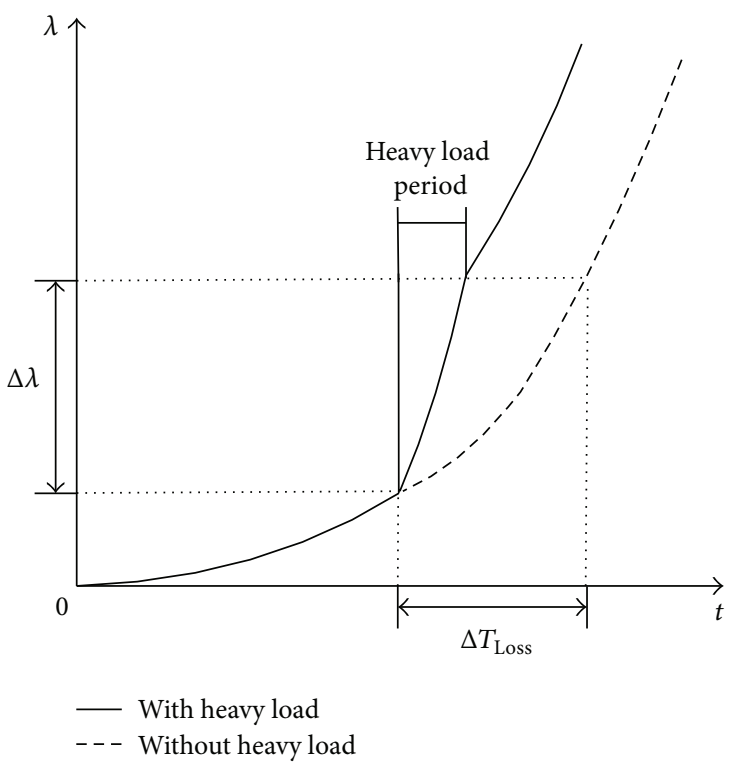

FIGURE 2: The impact of the heavy load on the insulation failure rate of transformers.

several corresponding failure rate components and has little impact on other components. After maintenance, the corresponding failure rate of this deterioration type returns to a certain initial value instead of that of the brand-new state [4]. Therefore, equipment's failure rate after maintenance can be obtained as

$$
\begin{aligned}
\lambda_{i}^{d}(t)=\max _{t^{\prime}=1}^{t}\left\{K_{i}^{d}\left(t^{\prime}+t_{i, \text { initial }}^{d}-1\right)\right. \\
\left.\times\left[1-\sum_{n=0}^{t^{\prime}-1} X_{i}^{d}(t-n)\right]\right\},
\end{aligned}
$$

where $K_{i}^{d}\left(t^{\prime}\right)$ denotes the failure rate of deterioration type $d$ on equipment $i$ in period $t^{\prime} . t_{i, \text { initial }}^{d}$ is the initial time duration after the previous maintenance for deterioration type $d$ of equipment $i$.

Aided by operation information in smart grids, the decoupled failure rate model accurately quantifies the impacts of operation conditions and maintenance activities on equipment reliability, serving as a basis for the distribution maintenance scheduling model presented below.

\section{Distribution System Maintenance Scheduling Model}

3.1. Objective Function. In system operation, both maintenance and failure may cause outages of equipment and reduce distribution system reliability. On one hand, equipment outages due to preventive maintenance may result in load shedding, thus decreasing systems' reliability level in maintenance periods. On the other hand, maintenance can reduce equipment's failure rates and improve the system 
reliability level in the following periods. To obtain the most economic preventive maintenance schedule, the influences of maintenance outages and failures should be comprehensively evaluated. Thus, the objective function is formulated as minimizing the total cost of the distribution system over the whole scheduling horizon $[4,19]$, which consists of three parts: the preventive maintenance cost, the corrective maintenance cost, and the penalty cost of lost load:

Minimize $f=\sum_{t=1}^{T_{\max }}\left\{\left(C^{M}(t)+C^{R}(t)\right.\right.$

$$
\left.\left.+C^{\mathrm{EENS}}(t)\right) \cdot(1+r)^{-t / 12}\right\}
$$

(i) $C^{M}(t)$-the preventive maintenance cost, which includes labour resource cost and materials cost of maintenance activities. The preventive maintenance cost in period $t$ is calculated as

$$
\begin{array}{r}
C^{M}(t)=\sum_{d=1}^{D} \sum_{i=1}^{N}\left(C_{\mathrm{p}-\mathrm{h}}^{d, M} \times L_{i}^{d, M}+S_{M, i}^{d, M}\right) X_{i}^{d}(t) \\
t=1,2, \ldots, T_{\text {max }}
\end{array}
$$

(ii) $C^{R}(t)$-the corrective maintenance cost, which is related to equipment's random failures rate $\lambda_{i}^{d}(t)$, so it is a probabilistic value and varies with time. Based on equipment's time-varying failure rate, $\lambda_{i}^{d}(t)$ in (2), the expected value of the system's repair cost in period $t$ is

$$
\begin{array}{r}
C^{R}(t)=\sum_{d=1}^{D} \sum_{i=1}^{N}\left(C_{\mathrm{p}-\mathrm{h}}^{d, R} \times L_{i}^{d, R}+S_{M, i}^{d, R}\right) \lambda_{i}^{d}(t) \\
t=1,2, \ldots, T_{\text {max }}
\end{array}
$$

(iii) $C^{\text {EENS }}(t)$ - the penalty cost of lost load. The penalty cost of lost load due to preventive maintenance, corrective maintenance, and failures is obtained from the reliability index Expected Energy not Served (EENS) as follows:

$$
C^{\mathrm{EENS}}(t)=I_{\mathrm{EAR}} E_{\mathrm{EENS}}\left(\lambda_{i}^{d}(t), X_{i}^{d}(t)\right) \quad t=1,2, \ldots, T_{\max },
$$

where $I_{\mathrm{EAR}}$ is the reliability value coefficient, which can be obtained from load composition analysis or customer surveys. $E_{\mathrm{EENS}}\left(\lambda_{i}^{d}(t), X_{i}^{d}(t)\right)$ denotes the expected energy not supplied in period $t$, which is calculated through reliability assessment of distribution systems using the network equivalence method and the minimal path method described in [23]. Observed from the corrective maintenance cost (7) and cost of lost load (8), it can be noted that decoupled failure rates $\lambda_{i}^{d}(t)$ are important data for the assessment of the system total cost.

\subsection{Constraints}

3.2.1. Maintenance Strategy Constraints. Maintenance strategy constraints are the constraints of maintenance activities [2], which include maintenance time window constraints, budget constraints, and labour constraints.

(i) Maintenance time window constraint: the starting period of preventive maintenance must be within a specific interval:

$$
T^{\mathrm{EAR}}\left(i, d_{i}\right) \leq T\left(i, d_{i}\right) \leq T^{\mathrm{LAT}}\left(i, d_{i}\right) \quad i=1,2, \ldots, N .
$$

For corrective maintenance, however, due to its high level of priority after a failure's occurrence, there is no time window constraint for it.

(ii) Budget constraint: cost in each period should be within the following budget:

$$
C^{\text {EENS }}(t)+C^{M}(t)+C^{R}(t) \leq C_{\text {budget }}(t) \quad t=1,2, \ldots, T_{\max } .
$$

(iii) Labour constraint: the maximum number of staff for preventive and corrective maintenance is limited:

$$
\begin{array}{r}
\sum_{i=1}^{N} \sum_{d=1}^{D}\left(L_{i}^{d, M} X_{i}^{d}(t)+L_{i}^{d, R} \lambda_{i}^{d}(t)\right) \leq L_{\text {ava }}(t) \\
t=1,2, \ldots, T_{\max } .
\end{array}
$$

3.2.2. System Operation Constraints. During maintenance, it is important to ensure a certain level of power supply reliability. The reliability indices-the System Average Interruption Frequency Index (SAIFI) and the System Average Interruption Duration Index (SAIDI), which, respectively, represent the frequency and duration of supply interruption, reflect the average level of power supply reliability in smart grid. In maintenance scheduling, system operation constraints are presented as follows.

(i) SAIFI constraint: to guarantee a certain power supply reliability level, SAIFI in each period should not exceed its limit $I_{\mathrm{SAIFI}}^{\mathrm{max}}$ :

$$
I_{\text {SAIFI }}\left(\lambda_{i}^{d}(t), X_{i}^{d}(t)\right) \leq I_{\mathrm{SAIFI}}^{\max } \quad t=1,2, \ldots, T_{\mathrm{max}},
$$

where $I_{\text {SAIFI }}\left(\lambda_{i}^{d}(t), X_{i}^{d}(t)\right)$ is SAIFI in period $t$.

(ii) SAIDI constraint: SAIDI in each period should not also exceed its limit $I_{\text {SAIDI }}^{\max }$ :

$$
I_{\mathrm{SAIDI}}\left(\lambda_{i}^{d}(t), X_{i}^{d}(t)\right) \leq I_{\mathrm{SAIDI}}^{\max } \quad t=1,2, \ldots, T_{\max },
$$

$$
\text { where } I_{\text {SAIDI }}\left(\lambda_{i}^{d}(t), X_{i}^{d}(t)\right) \text { is SAIDI in period } t \text {. }
$$

In smart grid, the values of $I_{\mathrm{SAIFI}}^{\mathrm{max}}$ and $I_{\mathrm{SAIDI}}^{\mathrm{max}}$ can be set to required reliability levels, which leads to different sizes of optimization (feasible) space for maintenance scheduling. 
The calculation of SAIFI and SAIDI involves complete procedures of distribution system reliability assessment as provided in $[23,24]$. Required data include the equipment reliability model in Section 2 and system configuration information. In addition, the power flow in some components of distribution systems is strictly limited. For these components, the overload constraint (14) should be satisfied during maintenance periods:

$$
\left|f_{i}(t)\right| \leq f_{i}^{\max } \quad t=1,2, \ldots, T_{\max },
$$

where $f_{i}^{\max }$ is power flow limit of component $i . f_{i}(t)$ is the power flow value of component $i$ in the peak-load mode during maintenance period $t$.

Distinguished from existing models that seldom consider various operation conditions, (1)-(14) presented a maintenance scheduling model that incorporated time-varying operation information and aimed to minimize the total cost, while subjected to power supply reliability requirements. To solve this model, a hybrid algorithm that derives from PSO and TS is designed and described as follows.

\section{The PSO-TS Hybrid Algorithm for the Maintenance Scheduling Model}

If the maintenance start time $T\left(i, d_{i}\right)$ is a discrete value for computational convenience, the above problem is an integer programming problem. Due to that $\lambda_{i}^{d}(t)$ is a nonlinear function of $t$ as shown in (2), constraint (11) is a nonlinear constraint. Moreover, since the reliability indices in the proposed model $\left(E_{\mathrm{EENS}}\left(\lambda_{i}^{d}(t), X_{i}^{d}(t)\right), I_{\mathrm{SAIFI}}\left(\lambda_{i}^{d}(t), X_{i}^{d}(t)\right)\right.$, and $\left.I_{\text {SAIDI }}\left(\lambda_{i}^{d}(t), X_{i}^{d}(t)\right)\right)$ involve the reliability assessment on the distribution system, they are nonlinear functions of $t$. So the formulated problem is an integer optimization problem with both nonlinear constraints and nonlinear objective function, to which conventional mathematical programming methods are difficult to apply. Metaheuristic methods, such as particle swarm optimization (PSO) and tabu search (TS), are suitable for solving this kind of nonlinear integer optimization problem. The PSO algorithm has the advantages of simplicity and high searching efficiency $[25,26]$, but it also has some drawbacks such as premature and immersing in local optimum [27]. Tabu search (TS) algorithm can easily generate many candidate solutions and expand the searching space [28]. So it has a strong and robust searching ability both globally and locally $[29,30]$, but its convergence is slow due to its relatively low searching efficiency and strong dependence on initial values.

Hybridized metaheuristic algorithms are considered to be effective and efficient in solving large-scale optimization problems [31]. Based on the principles of hybridizing metaheuristic algorithms and the characteristics of the maintenance scheduling model, this paper proposes the solving process of a PSO-TS hybrid algorithm for the maintenance scheduling problem, which is presented in Figure 3.

Details of some steps are explained below.

Step (1). Input the problem data and the algorithm parameters. The required data include equipment data of the distribution system, load data, operation condition data, and system configuration information. The equipment data consist of equipment deterioration data, preventive maintenance data, and corrective maintenance data. Load data include node load data and required power supply reliability (i.e., CAIFI and CAIDI) constraints.

Step (2). Particles' positions, velocities, and the tabu list are initialized considering constraints in (9)-(14). The position vector of a particle denotes maintenance starting periods of different equipment.

Step (5). Particles' positions and velocities are updated according to (15), while considering constraints in (9)-(14). Particles remain motionless if they do not satisfy constraints after being updated:

$$
\begin{aligned}
\Delta T_{j}^{s+1}\left(i, d_{i}\right)= & \omega \cdot \Delta T_{j}^{s}\left(i, d_{i}\right) \\
& +c_{1} \cdot \operatorname{rand}_{1}() \cdot\left(T_{j}^{s, \text { Best }}\left(i, d_{i}\right)-T_{j}^{s}\left(i, d_{i}\right)\right) \\
& +c_{2} \cdot \operatorname{rand}_{2}() \cdot\left(T^{s, \text {Best}}\left(i, d_{i}\right)-T_{j}^{s}\left(i, d_{i}\right)\right), \\
T_{j}^{s+1}\left(i, d_{i}\right)= & T_{j}^{s}\left(i, d_{i}\right)+\Delta T_{j}^{s+1}\left(i, d_{i}\right) .
\end{aligned}
$$

A difference between the PSO part in this algorithm and PSO in current research $[27,32]$ is the adaptive inertia weight, the formulation of which is presented in (16). To improve PSO's searching ability, the inertia weight $\omega$ in this paper decreases nonlinearly as iterations increase and the particles' dispersion degree $\Delta$ decreases, both of which affect the inertia weight simultaneously in the iterative process:

$$
\begin{array}{r}
\omega=\frac{1}{\left\{1+\exp \left[\left((a+b) \cdot(1-\Delta) \cdot s / I_{\text {iter }}^{\max }\right)-b\right]\right\}}, \\
\omega \in\left[\omega_{\min }, \omega_{\max }\right],
\end{array}
$$

where $s$ is the iteration number and $I_{\mathrm{iter}}^{\max }$ is the maximum iteration number. Coefficients $a$ and $b$ can be calculated supposing $\omega=\omega_{\max }$ at the beginning of iteration (i.e., $s=0$ ) and $\omega=$ $\omega_{\min }$ at the end of iteration (i.e., $s=I_{\text {iter }}^{\max }$ [ [33]. $\Delta$ describes the current dispersion degree of the particle swarm, which is calculated as follows:

$$
\Delta=\frac{\left(M_{\text {MaxDist }}-M_{\text {MeanDist }}\right)}{M_{\text {MaxDist }}},
$$

where $M_{\text {MeanDist }}$ and $M_{\text {MaxDist }}$ denote the average and the maximum distance of current particles from the best position obtained, which are calculated as follows, respectively:

$$
\begin{gathered}
M_{\text {MeanDist }}=\frac{\left\{\sum_{j=1}^{N_{P}} \sqrt{\sum_{i=1}^{N}\left(T^{s, \text { Best }}\left(i, d_{i}\right)-T_{j}^{s}\left(i, d_{i}\right)\right)^{2}}\right\}}{N_{P}} . \\
M_{\text {MaxDist }}=\max _{j=1,2, \ldots, N_{P}}\left\{\sqrt{\sum_{i=1}^{N}\left(T^{s, \text {Best}}\left(i, d_{i}\right)-T_{j}^{s}\left(i, d_{i}\right)\right)^{2}}\right\} .
\end{gathered}
$$




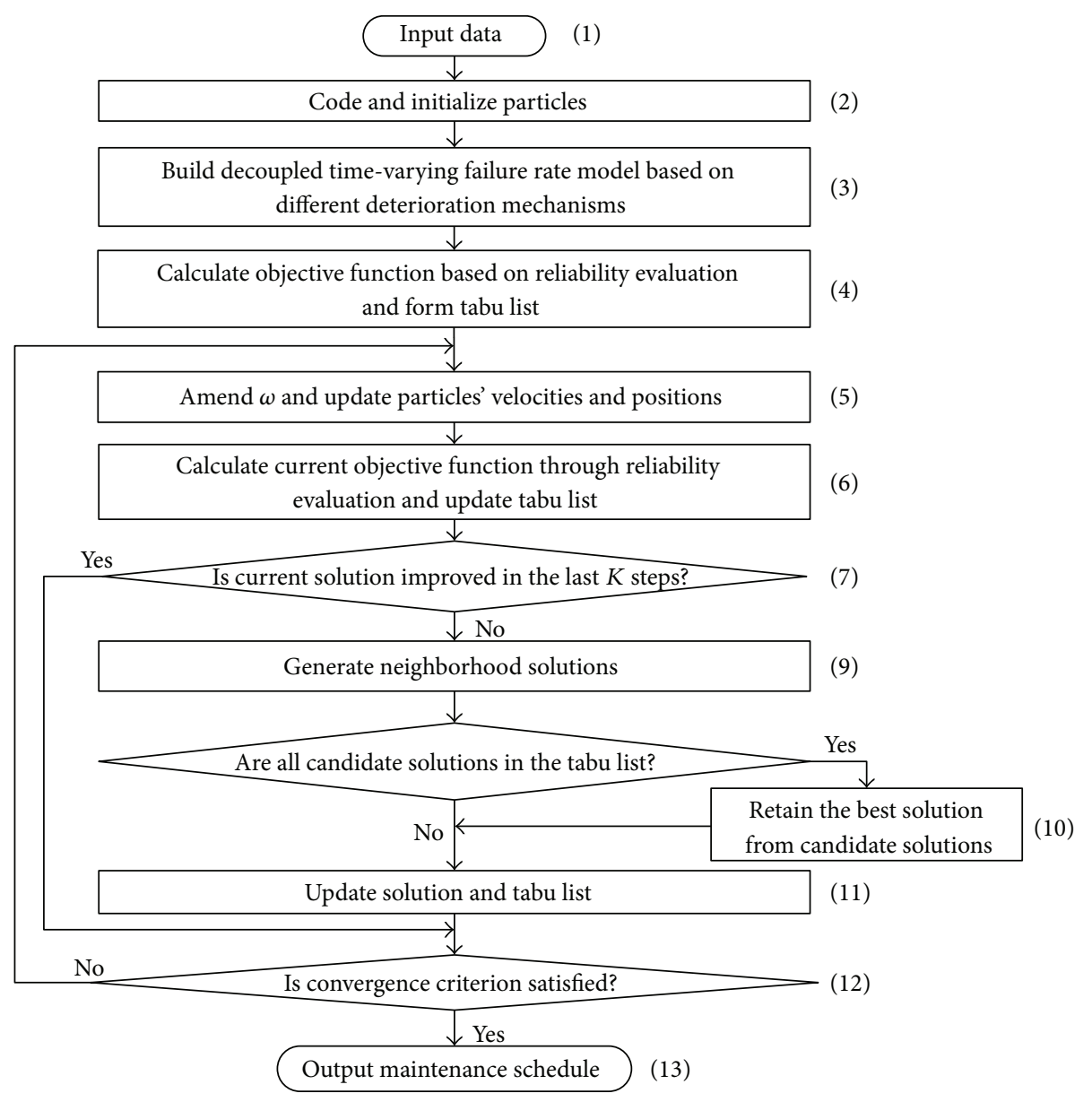

FIGURE 3: The solving flow chart through the PSO-TS hybrid algorithm for maintenance scheduling.

Step (8). In forming neighbourhood solutions, each element (maintenance starting period) of the particle is assigned a new and random value which is within its permitted maintenance interval. When all the elements are moved successively, all the obtained feasible and nontabooed solutions are the current particle's neighbourhood solutions. The neighbourhood move of TS pulls the solution out of local optimum and improves the global searching ability.

Steps (9-10). These two steps describe the aspiration criterion, which amnesties the tabooed solution and is used to update the current solution. The aspiration criterion in this algorithm is satisfying one of the two conditions. (a) A candidate solution, whose objective value is smaller than that of the current optimum solution, is amnestied. (b) When all the candidate solutions are in the tabu list, the solution with the minimum objective value is amnestied.

Step (12). The optimization process stops when one of the following termination criteria is satisfied. (a) The number of iterations exceeds its limit. (b) The objective function value does not change during a given number of iterations.

The PSO-TS hybrid algorithm inherits PSO's advantage of fast optimization speed, while adopting the neighbourhood move and the tabu list of TS to escape from local cycle to enhance its global searching ability, thus facilitating fast and continuous improvement of the solution during the optimization process.

\section{Case Study}

\subsection{Case Data}

5.1.1. System Data. The distribution system formed by Feeder 1 and Feeder 2 on Bus 6 in IEEE RBTS [34] (referred to as the F1 and F2 distribution systems) is selected as the test system. The scheduling time horizon is 60 months. The proposed model and algorithm are assumed to serve as a function component of the asset management module, which constitutes part of the smart grid control centre for the F1 and F2 distribution systems. The load curve of every month is obtained by modifying the load data given by [35] with an annual increase of $5 \%$. According to the equipment data provided by [36], the isolation switches' operation time is one hour. The reliability rates of fuses and breakers are 1.0 and 0.8 , respectively. The electricity price and the annual interest rate are $50 \$ \cdot \mathrm{MWh}^{-1}$ and $10 \%$, respectively. The cost of per unit 
TABLE 1: Deterioration mechanisms data of $11 \mathrm{kV}$ feeder distribution system.

\begin{tabular}{lcccc}
\hline $\begin{array}{l}\text { Deterioration } \\
\text { mechanism type }\end{array}$ & Coefficient & Line & Transformer & Breaker \\
\hline & $\alpha 1$ & 11.47 & 11.47 & 11.47 \\
Type 1 (Tp1) & $\beta 1$ & 0.2651 & 0.2651 & 0.2651 \\
& $\alpha 2$ & 76.262 & 79.452 & 75.452 \\
& $\beta 2$ & 4.4792 & 4.4792 & 4.2792 \\
& $h$ & 0.00866 & 0.00866 & 0.00866 \\
\hline & $\alpha 1$ & 16.38 & 15.38 & 15.38 \\
Type 2 (Tp2) & $\beta 1$ & 0.3759 & 0.3559 & 0.3559 \\
& $\alpha 2$ & 98.045 & 92.045 & 87.045 \\
& $\beta 2$ & 5.964 & 5.064 & 4.4792 \\
& $h$ & 0.02673 & 0.02673 & 0.02673 \\
\hline & $\alpha 1$ & 25.64 & 25.64 & 25.64 \\
Type 3 (Tp3) & $\beta 1$ & 0.2873 & 0.2873 & 0.2873 \\
& $\alpha 2$ & 94.12 & 90.36 & 90.294 \\
& $\beta 2$ & 5.954 & 5.028 & 5.028 \\
& $h$ & 0.03512 & 0.03512 & 0.03512 \\
\hline
\end{tabular}

lost load is set to $400 \$ \cdot \mathrm{MWh}^{-1}$ [37]. The maintenance of lines, transformers, and breakers is considered. It is assumed that, for lines, transformers, and breakers, each has three types of deterioration mechanisms. Weibull distribution parameters of these deterioration mechanisms are provided by [19] as shown in Table 1.

5.1.2. Maintenance Data and Algorithm Coefficients. The preventive and corrective maintenance data of the test system are shown in Table 2.

Despite the fact that the proposed method is also capable of solving a large-scale problem that considers all equipment's maintenance and all their deterioration processes, not all equipment's maintenance arrangements are considered in this case for simplicity. The maintenance-needed equipment and constraints are shown in Tables 3 and 4 , respectively. The number of particles is 30 . The size of the tabu list is set to 7 (the integer near $\sqrt{N}$ ). Parameters of the algorithm in (16)(19) are set as follows: $c 1$ and $c 2$ are both set to 2.0 according to [38]. $\omega_{\min }$ and $\omega_{\max }$ are set to 0.4 and 0.9 , respectively [33]. Based on (16) and the common assumption that $\omega$ starts with $\omega_{\max }=0.9$ and decreases to $\omega_{\min }=0.4$ through the course of run [33], values of $a$ and $b$ in (16) can be obtained as 0.4 and 2.2, respectively. Considering the searching performance and computation time of PSO and TS algorithm, $K$, the maximum iteration number of PSO without improvement in the objective value before turning to the TS searching mode, is set to 5 .

5.2. Maintenance Scheduling Based on Historical Operation Information. Based on historical operation data and equipment's deterioration characteristics, the expected change of equipment's reliability can be calculated. As an example, transformer T13's time-varying failure rate curves are shown

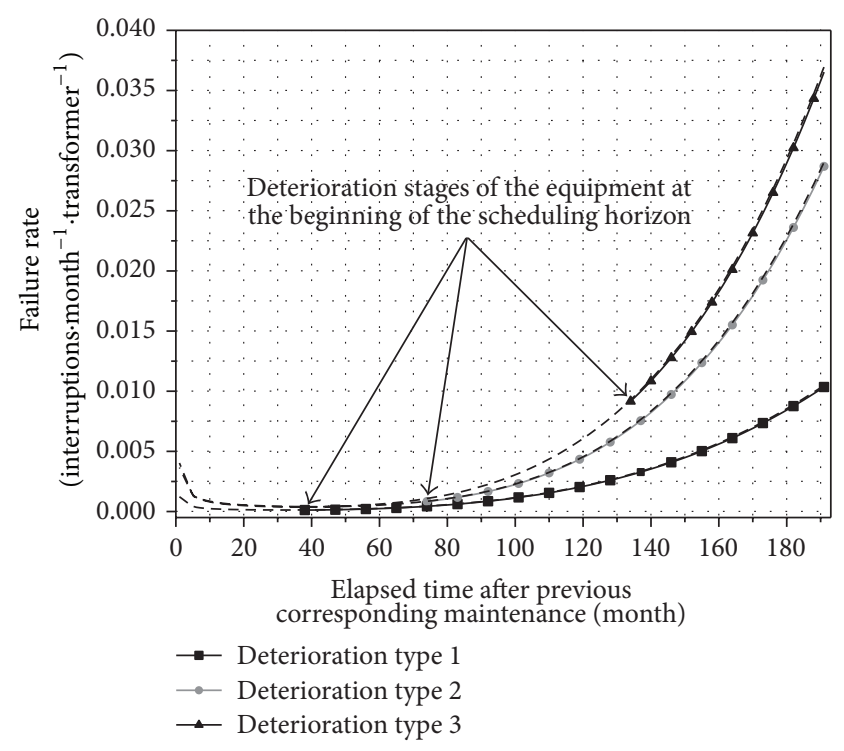

FIGURE 4: Reliability model of the transformer T13.

in Figure 4. The three lines in Figure 4 denote the three deterioration mechanisms' failure rate components of T13 after previous maintenance. The tagged line segments represent the three failure development processes from the beginning of the scheduling horizon.

The maintenance scheduling is optimized based on equipment's reliability model in Section 2 and the maintenance scheduling model proposed in Section 3. The model and algorithm are implemented in $\mathrm{C}++$ and run on a $\mathrm{PC}$ with Core2 E7300 CPU and 3.5 GB RAM. The total running time is about 87 minutes, most of which is used for the reliability assessment in each maintenance period. Since long-term maintenance scheduling horizons for distribution systems are usually several years, this computational time is acceptable in engineering application. The compositions of the total cost during iterations are shown in Figure 5.

It can be noted that in the early stage, the PSO algorithm has high search efficiency and the system total cost decreases rapidly. However, particles may immerse into the local nearoptimal solution cycles after several PSO iterations, and the accuracy of the solution cannot be further improved. For example, from the 12th to the 16th iteration step, a nearoptimal solution cycle emerges, in which the total cost of the distribution system is $\$ 307,025$. From the 16th step, the algorithm turns to the TS mode and generates candidate solutions to expand the searching space through adding the local optimum to the tabu list. The neighbourhood move of TS helps to jump out of local optimum and find more accurate global optimum simultaneously. After the 17th iteration step (TS iteration), the solution gets rid of the local solution cycle and the total cost declines to $\$ 304,804$. In the 29th iteration step, the objective value decreases to $\$ 281,929$. This value remains unchanged during the next five PSO iterations and five TS iterations as shown in Figure 5, indicating the satisfaction of the termination criterion (b). The optimization result of maintenance scheduling and the reliability indices 
TABLE 2: Maintenance data of different deterioration mechanism types and equipment.

\begin{tabular}{|c|c|c|c|c|c|c|c|c|c|}
\hline \multirow{2}{*}{ Equipment } & \multicolumn{3}{|c|}{ Duration (h) } & \multicolumn{3}{|c|}{ Labour (p-h) } & \multicolumn{3}{|c|}{ Materials cost $(\$)$} \\
\hline & Tp1 & $\mathrm{Tp} 2$ & $\mathrm{Tp} 3$ & Tp1 & $\mathrm{Tp} 2$ & $\mathrm{Tp} 3$ & Tp1 & $\mathrm{Tp} 2$ & $\mathrm{Tp} 3$ \\
\hline \multicolumn{10}{|c|}{ Preventive maintenance } \\
\hline Line (per km) & 2 & 4 & 6 & 3 & 10 & 20 & 12.5 & 50 & 125 \\
\hline Transformer & 4 & 8 & 10 & 5 & 15 & 33 & 30 & 70 & 300 \\
\hline Breaker & 3 & 6 & 9 & 4 & 12 & 24 & 25 & 60 & 250 \\
\hline \multicolumn{10}{|c|}{ Corrective maintenance } \\
\hline Line (per km) & 7 & 10 & 14 & 8 & 15 & 30 & 25 & 100 & 275 \\
\hline Transformer & 10 & 15 & 20 & 12 & 25 & 50 & 60 & 190 & 600 \\
\hline Breaker & 9 & 13 & 18 & 10 & 20 & 40 & 50 & 150 & 500 \\
\hline
\end{tabular}

TABle 3: Preventive maintenance (PM) needed equipment.

\begin{tabular}{|c|c|c|c|}
\hline Maintenance type & \multicolumn{3}{|c|}{ Equipment to be scheduled for preventive maintenance } \\
\hline PM Tp1 & Bus: B3 & $\begin{array}{l}\text { Line: L2, L3, L4, L5, L6, L8, L9, L10, } \\
\text { L11, L12, L13, L16, L17, L18, L21, } \\
\text { L22, L24, L25, L26 }\end{array}$ & $\begin{array}{l}\text { Transformer: T7, T9, T11, } \\
\text { T15, T25, T29, T31, T35 }\end{array}$ \\
\hline PM Tp2 & Bus: B4 & Line: L7, L15, L20, L23 & Transformer: T5, T23 \\
\hline PM Tp3 & & Line: L1, L14, L19 & Transformer: T13, T27, T33 \\
\hline
\end{tabular}

TABle 4: Maintenance and system operation constraints in one period.

\begin{tabular}{lc}
\hline Constraints & Limit value \\
\hline Budget constraints $(\$)$ & 30,000 \\
Labour constraints (person-hour) & 85 \\
SAIFI (interruption $\cdot$ month $^{-1}$ ) & 1.75 \\
SAIDI $\left(h \cdot \mathrm{month}^{-1}\right.$ ) & 10 \\
\hline
\end{tabular}

of the optimum solution are shown in Table 5 and Figure 6, respectively.

Since this algorithm is a stochastic algorithm, 30 independent runs have been performed. The mean value of the result is $\$ 282,630$ and the standard deviation is $\$ 853$. The relative error is about $0.3 \%$. The results indicate that the algorithm has good accuracy and can guarantee to obtain the optimal solution.

\subsection{The Maintenance Scheduling Result Incorporating Future} Operation Information. In smart grids, some future operation information is available through forecasting or presetting. Here, a future heavy load scenario is taken, for instance. It is assumed that the load on node 5 is 2.1 times of its original value during periods 12 and 13. Based on calculation through (3), if no maintenance is performed on T13 over the planning horizon, its time-varying failure rate due to insulation aging is shown by the dotted line in Figure 7.

The optimal maintenance schedule considering future heavy load scenario is presented in Table 6. Through the comparison of Tables 5 and 6 , the maintenance starting period of T13 was moved from period 22 to period 7. This transition shows that the preventive maintenance of some equipment should be performed in advance in case of

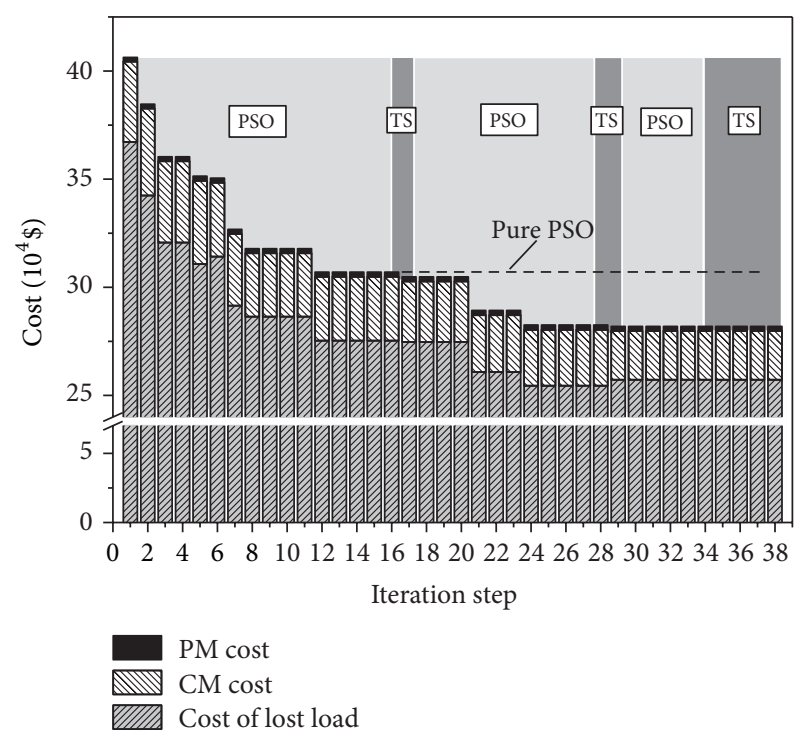

FIGURE 5: Composition of the total cost in the iteration process.

predictable future heavy load scenarios, because preventive maintenance before heavy load avoids equipment reaching its late aging stage in which the failure rate increases sharply during heavy load periods, thus reducing system failure risks and the total cost. The result verifies that the incorporation of future operation information into maintenance scheduling in smart grids helps to obtain a more economical solution.

5.4. Sensitivity Analysis on Reliability Requirements. In Figure 8, the point-linked lines represent the reliability indices of the maintenance scheduling result with ordinary power supply reliability requirements. In order to analyse the 
TABLE 5: Maintenance scheduling result ( $T_{\mathrm{MS}}$ stands for the maintenance starting period).

\begin{tabular}{lcccccccccccc}
\hline Number & $T_{\text {MS }}$ & Number & $T_{\text {MS }}$ & Number & $T_{\text {MS }}$ & Number & $T_{\text {MS }}$ & Number & $T_{\text {MS }}$ & Number & $T_{\text {MS }}$ \\
\hline L1 & 4 & L8 & 46 & L15 & 35 & L22 & 9 & T9 & 17 & T29 & 22 \\
L2 & 28 & L9 & 27 & L16 & 9 & L23 & 15 & T11 & 23 & T31 & 43 \\
L3 & 39 & L10 & 20 & L17 & 46 & L24 & 16 & T13 & 22 & T33 & 4 \\
L4 & 46 & L11 & 44 & L18 & 33 & L25 & 33 & T15 & 20 & T35 & 27 \\
L5 & 9 & L12 & 28 & L19 & 15 & L26 & 29 & T23 & 3 & B4 & 22 \\
L6 & 21 & L13 & 29 & L20 & 21 & T5 & 27 & T25 & 21 & B3 & 40 \\
L7 & 44 & L14 & 3 & L21 & 11 & T7 & 5 & T27 & 3 & \\
\hline
\end{tabular}

TABLE 6: Maintenance scheduling result with future heavy load scenarios.

\begin{tabular}{lccccccccccc}
\hline Number & $T_{\text {MS }}$ & Number & $T_{\text {MS }}$ & Number & $T_{\text {MS }}$ & Number & $T_{\text {MS }}$ & Number & $T_{\text {MS }}$ & Number & $T_{\text {MS }}$ \\
\hline L1 & 10 & L8 & 52 & L15 & 27 & L22 & 31 & T9 & 27 & T29 & 20 \\
L2 & 4 & L9 & 27 & L16 & 37 & L23 & 5 & T11 & 31 & T31 & 22 \\
L3 & 1 & L10 & 25 & L17 & 41 & L24 & 19 & T13 & 7 & T33 & 6 \\
L4 & 16 & L11 & 7 & L18 & 48 & L25 & 50 & T15 & 36 & T35 & 13 \\
L5 & 17 & L12 & 11 & L19 & 9 & L26 & 22 & T23 & 15 & B4 & 37 \\
L6 & 42 & L13 & 30 & L20 & 14 & T5 & 15 & T25 & 16 & B3 & 39 \\
L7 & 17 & L14 & 16 & L21 & 47 & T7 & 28 & T27 & 2 & \\
\hline
\end{tabular}

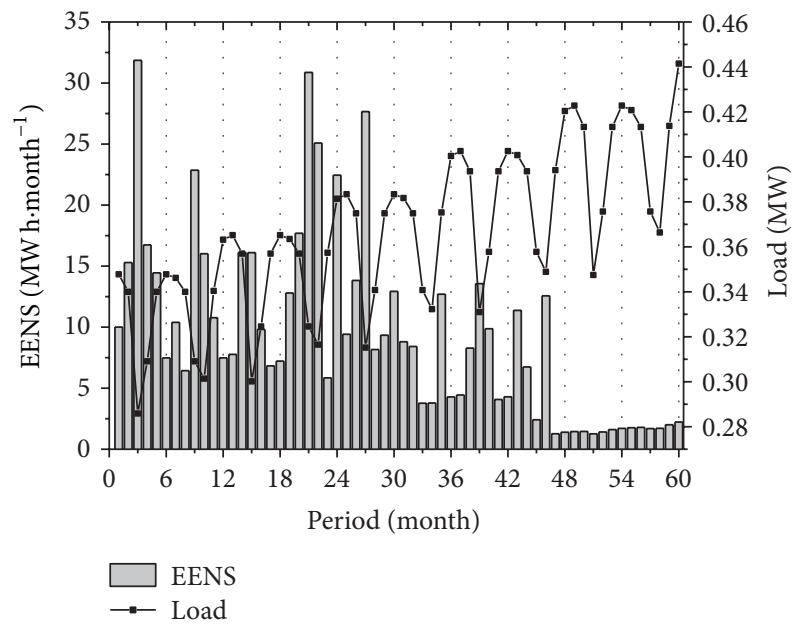

FIGURE 6: EENS of each period of the scheduling result.

sensitivity of the result to reliability requirements, SAIFI and SAIDI are further constrained to 1.5 interruptions $\cdot$ month $^{-1}$ and $8 \mathrm{~h} \cdot \mathrm{month}^{-1}$, respectively, to simulate a higher reliability requirement. Reliability indices in each period of the new scheduling result are represented by the grey columns in Figure 8. A comparison on the total system costs over the scheduling horizon between two schedules is shown in Table 7.

As shown in Figure 8, when the reliability constraints are stricter, the number of maintenance activities in each period will be further limited. As a result, the values of system reliability indices are more evenly distributed over the scheduling horizon. However, as shown in Table 7, despite the fact that the maximum values of SAIFI and SAIDI decrease

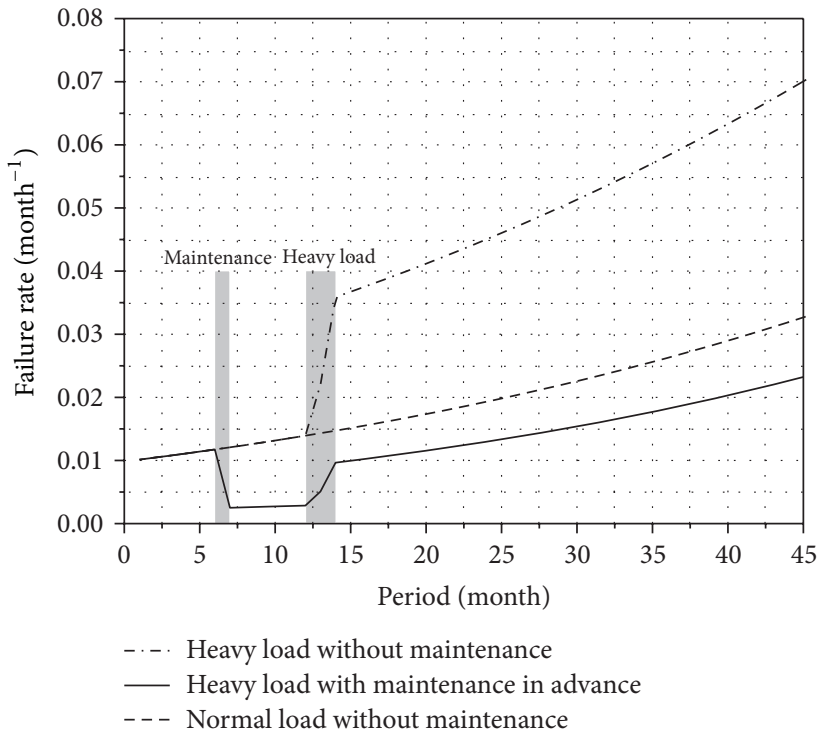

FIGURE 7: T13's insulation failure rate change with heavy load and maintenance.

as reliability constraints become stricter, the penalty cost of lost load and total cost over the whole scheduling horizon increase by $4.33 \%$ and $4.30 \%$, respectively. This indicates that higher reliability requirements would result in an increase of the total cost over the planning horizon. This quantitative analysis would help the pricing of electricity supply with different levels of reliability for electricity retailers. Under the framework of smart grids, it also provides basic information on reliability/economy for the interaction between customers and smart grids. 
TABLE 7: System cost with different reliability requirements.

\begin{tabular}{lcc}
\hline Cost & $\begin{array}{c}\text { Ordinary constraints }(\$) \\
\text { Lost load penalty }\end{array}$ & $\begin{array}{c}\text { Stricter constraints }(\$) \\
\left.\text { (SAIFI } \leq 1.75 \text { month }^{-1}, \text { SAIDI } \leq 10 \mathrm{~h} \cdot \mathrm{month}^{-1}\right)\end{array}$ \\
Corrective maintenance & $257,278.0$ & $268,927.0$ \\
Preventive maintenance & $22,495.7$ & $23,531.1$ \\
\hline Total & $2,156.0$ & $2,137.5$ \\
\hline
\end{tabular}
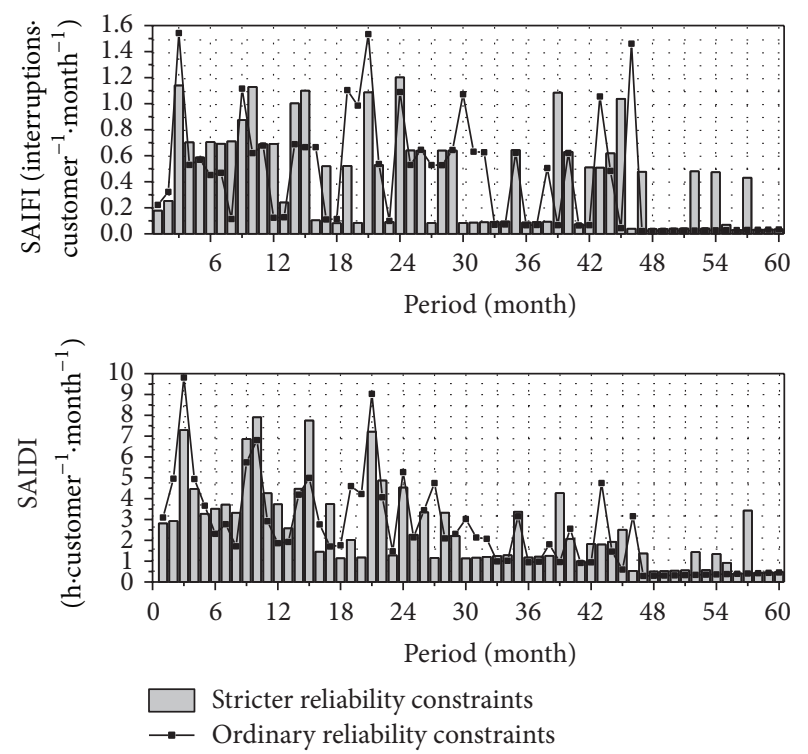

FIGURE 8: Reliability indices of each period with stricter reliability constraints.

\section{Conclusions}

This paper proposed a long-term distribution maintenance scheduling model for asset management in smart grid to minimize the total cost over the maintenance scheduling horizon. Based on data collected by smart meters and sensors in distribution systems, the decoupled failure rate model is more adaptable and accurate to represent the time-varying failure rates due to different deterioration mechanisms. It is proved that the incorporation of operation conditions into maintenance scheduling helps to make a more economic and reasonable schedule. The PSO-TS hybrid algorithm used in this paper avoids the local optimum of PSO and low searching efficiency of TS, showing good applicability to the nonlinear integer programming problem. Numerical results show that the proposed model and algorithm have good potential for long-term distribution system maintenance scheduling in smart grid.

\section{Notations}

$C_{\text {budget }}(t)$ : Maximum budget provided in period $t$

$C_{\mathrm{p}-\mathrm{h}}^{d, M}: \quad$ The cost of one person-hour in preventive maintenance type $d$

$C_{\mathrm{p}-\mathrm{h}}^{d, R}: \quad$ The cost of one person-hour in corrective maintenance type $d$ $d: \quad$ The deterioration type index (i.e., preventive and corrective maintenance type index)

D: $\quad$ The number of deterioration types (i.e., number of preventive and corrective maintenance types)

$L_{\text {ava }}(t): \quad$ Labour resources (in person-hours) available in period $t$

$L_{i}^{d, M}$ : $\quad$ Labour resources (in person-hours) required in preventive maintenance type $d$ on equipment $i$

$L_{i}^{d, R}: \quad$ Labour resources (in person-hours) required in corrective maintenance type $d$ on equipment $i$

$N$ : $\quad$ The number of maintenance-needed equipment

$N_{p}: \quad$ The size of the particle swarm in PSO

$r: \quad$ The annual interest rate

$S_{M, i}^{d, M}: \quad$ The materials cost required in preventive maintenance type $d$ on equipment $i$

$S_{M, i}^{d, R}: \quad$ The materials cost required in corrective maintenance type $d$ on equipment $i$

$T_{\max }: \quad$ The time horizon of maintenance scheduling

$T^{\mathrm{EAR}}\left(i, d_{i}\right)$ : The earliest feasible starting period of preventive maintenance type $d$ on equipment $i$

$T^{\mathrm{LAT}}\left(i, d_{i}\right)$ : The latest feasible starting period of preventive maintenance type $d$ on equipment $i$

$T\left(i, d_{i}\right): \quad$ The starting period of preventive maintenance type $d$ on equipment $i$

$T_{j}\left(i, d_{i}\right): \quad$ The starting period of preventive maintenance type $d$ on equipment $i$ in particle $j$

$T_{j}^{s, \text { Best }}\left(i, d_{i}\right)$ : The starting period of preventive maintenance type $d$ on equipment $i$ in historical optimal solution of particle $j$

$T^{s, \text { Best }}\left(i, d_{i}\right)$ : The starting period of preventive maintenance type $d$ on equipment $i$ in historical optimal solution of the particle swarm

$X_{i}^{d}(t): \quad$ A binary ancillary variable, which equals 1 if preventive maintenance type $d$ on equipment $i$ is conducted in period $t$ and equals 0 otherwise. 


\section{Conflict of Interests}

The authors declare that there is no conflict of interests regarding the publication of this paper.

\section{Acknowledgment}

This work was supported by the National Natural Science Foundation of China (nos. 51277141 and 50807043).

\section{References}

[1] T. Nakagawa, Maintenance Theory of Reliability, Springer, Berlin, Germany, 2005.

[2] S. R. K. Yeddanapudi, Y. Li, J. D. McCalley, A. A. Chowdhury, and W. T. Jewell, "Risk-based allocation of distribution system maintenance resources," IEEE Transactions on Power Systems, vol. 23, no. 2, pp. 287-295, 2008.

[3] H. Mohammadnezhad-Shourkaei, A. Abiri-Jahromi, and M. Fotuhi-Firuzabad, "Incorporating service quality regulation in distribution system maintenance strategy," IEEE Transactions on Power Delivery, vol. 26, no. 4, pp. 2495-2504, 2011.

[4] A. Abiri-Jahromi, M. Fotuhi-Firuzabad, and E. Abbasi, "An efficient mixed-integer linear formulation for long-term overhead lines maintenance scheduling in power distribution systems," IEEE Transactions on Power Delivery, vol. 24, no. 4, pp. 20432053, 2009.

[5] H. Y. Zhao, G. Y. Liu, H. J. Jia et al., "Analysis of residential loads behaviors integrated with distributed generation under different pricing scenarios," Applied Mechanics and Materials, vol. 385, pp. 1025-1029, 2013.

[6] L. Bertling, R. Allan, and R. Eriksson, "A reliability-centered asset maintenance method for assessing the impact of maintenance in power distribution systems," IEEE Transactions on Power Systems, vol. 20, no. 1, pp. 75-82, 2005.

[7] J. H. Heo, M. K. Kim, G. P. Park et al., "A reliability-centered approach to an optimal maintenance strategy in transmission systems using a genetic algorithm," IEEE Transactions on Power Delivery, vol. 26, no. 4, pp. 2171-2179, 2011.

[8] J. Endrenyi, S. Aboresheid, R. N. Allan et al., "The present status of maintenance strategies and the impact of maintenance on reliability," IEEE Transactions on Power Systems, vol. 16, no. 4, pp. 638-646, 2001.

[9] A. D. Janjic and D. S. Popovic, "Selective maintenance schedule of distribution networks based on risk management approach," IEEE Transactions on Power Systems, vol. 22, no. 2, pp. 597-604, 2007.

[10] Y. Jiang, J. D. McCalley, and T. Van Voorhis, "Risk-based resource optimization for transmission system maintenance," IEEE Transactions on Power Systems, vol. 21, no. 3, pp. 1191-1200, 2006.

[11] F. Li and R. E. Brown, "A cost-effective approach of prioritizing distribution maintenance based on system reliability," IEEE Transactions on Power Delivery, vol. 19, no. 1, pp. 439-441, 2004.

[12] G.-P. Park and Y. T. Yoon, "Application of ordinal optimization on reliability centered maintenance of distribution system," European Transactions on Electrical Power, vol. 22, no. 3, pp. 391-401, 2012.

[13] A. Sittithumwat, F. Soudi, and K. Tomsovic, "Optimal allocation of distribution maintenance resources with limited information," Electric Power Systems Research, vol. 68, no. 3, pp. 208220, 2004.
[14] S. K. Abeygunawardane and P. Jirutitijaroen, "New state diagrams for probabilistic maintenance models," IEEE Transactions on Power Systems, vol. 26, no. 4, pp. 2207-2213, 2011.

[15] P. A. Kuntz, R. D. Christie, and S. S. Venkata, "Optimal vegetation maintenance scheduling of overhead electric power distribution systems," IEEE Transactions on Power Delivery, vol. 17, no. 4, pp. 1164-1169, 2002.

[16] R. Billinton, S. Kumar, N. Chowdhury et al., "Reliability test system for educational purposes-basic data," IEEE Transactions on Power Systems, vol. 4, no. 3, pp. 1238-1244, 1989.

[17] Y. Pan and M. U. Thomas, "Repair and replacement decisions for warranted products under markov deterioration," IEEE Transactions on Reliability, vol. 59, no. 2, pp. 368-373, 2010.

[18] J. Endrenyi and G. J. Anders, "Aging, maintenance, and reliability," IEEE Power and Energy Magazine, vol. 4, no. 3, pp. 59-67, 2006.

[19] C. Feng and X. Wang, "A competitive mechanism of unit maintenance scheduling in a deregulated environment," IEEE Transactions on Power Systems, vol. 25, no. 1, pp. 351-359, 2010.

[20] W. J. McNutt, "Insulation thermal life considerations for transformer loading guides," IEEE Transactions on Power Delivery, vol. 7, no. 1, pp. 392-401, 1992.

[21] A. M. Emsley, X. Xiao, R. J. Heywood, and M. Ali, “Degradation of cellulosic insulation in power transformers. Part 3. Effects of oxygen and water on ageing in oil," IEE Proceedings: Science, Measurement and Technology, vol. 147, no. 3, pp. 115-119, 2000.

[22] "IEEE Std C57. 91: IEEE guide for loading mineral-oil-immersed transformers," in Transformers Committee of the IEEE Power Engineering Society, IEEE Standards Board, 1995.

[23] R. E. Brown, Electric Power Distribution Reliability, CRC Press, New York, NY, USA, 2002.

[24] R. Billinton and R. N. Allan, Reliability Evaluation of Power Systems, Plenum press, New York, NY, USA, 1984.

[25] Y. Yare, G. K. Venayagamoorthy, and U. O. Aliyu, "Optimal generator maintenance scheduling using a modified discrete PSO," IET Generation, Transmission and Distribution, vol. 2, no. 6, pp. 834-846, 2008.

[26] P. Hilber, V. Miranda, M. A. Matos, and L. Bertling, "Multiobjective optimization applied to maintenance policy for electrical networks," IEEE Transactions on Power Systems, vol. 22, no. 4, pp. 1675-1682, 2007.

[27] T. Zhang, T. Hu, Y. Zheng et al., "An improved particle swarm optimization for solving bilevel multiobjective programming problem," Journal of Applied Mathematics, vol. 2012, Article ID 626717, 13 pages, 2012.

[28] J. Kluabwang, D. Puangdownreong, and S. Sujitjorn, "Multipath adaptive tabu search for a vehicle control problem," Journal of Applied Mathematics, vol. 2012, Article ID 731623, 20 pages, 2012.

[29] I. J. Ramirez-Rosado and J. A. Dominguez-Navarro, "New multiobjective Tabu search algorithm for fuzzy optimal planning of power distribution systems," IEEE Transactions on Power Systems, vol. 21, no. 1, pp. 224-233, 2006.

[30] M. Gopalakrishnan, S. Mohan, and Z. He, "A tabu search heuristic for preventive maintenance scheduling," Computers and Industrial Engineering, vol. 40, no. 1-2, pp. 149-160, 2001.

[31] G. Zhang, X. Shao, P. Li, and L. Gao, "An effective hybrid particle swarm optimization algorithm for multi-objective flexible jobshop scheduling problem," Computers and Industrial Engineering, vol. 56, no. 4, pp. 1309-1318, 2009. 
[32] A. Nickabadi, M. M. Ebadzadeh, and R. Safabakhsh, "A novel particle swarm optimization algorithm with adaptive inertia weight," Applied Soft Computing Journal, vol. 11, no. 4, pp. 36583670, 2011.

[33] Y. Shi and R. C. Eberhart, "Empirical study of particle swarm optimization," in Proceedings of the IEEE Congress on Evolutionary Computation (CEC '99), Washington, DC, USA, 1999.

[34] R. Billinton and S. Jonnavithula, "A test system for teaching overall power system reliability assessment," IEEE Transactions on Power Systems, vol. 11, no. 4, pp. 1670-1676, 1996.

[35] A. Anon, "IEEE reliability tests system," IEEE Transaction on Power Apparatus and Systems, vol. 98, no. 6, pp. 2047-2054, 1979.

[36] R. N. Allan, R. Billinton, I. Sjarief, L. Goel, and K. S. So, "A reliability test system for educational purposes-basic distribution system data and results," IEEE Transactions on Power Systems, vol. 6, no. 2, pp. 813-820, 1991.

[37] X. Tan and Z. Hu, "Further study on value of lost load based on input-output method," Power System Technology, vol. 1, p. 15, 2008 (Chinese).

[38] Y. Shi and R. Eberhart, "Modified particle swarm optimizer," in Proceedings of the IEEE International Conference on Evolutionary Computation (ICEC '98), pp. 69-73, May 1998. 


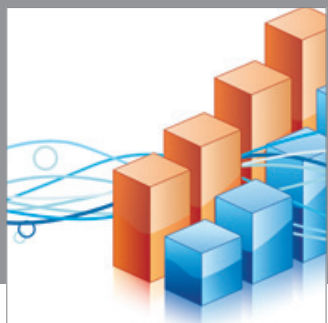

Advances in

Operations Research

mansans

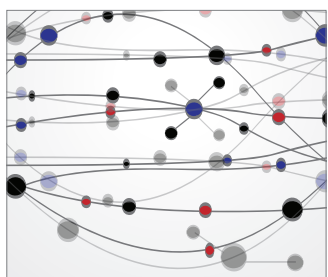

The Scientific World Journal
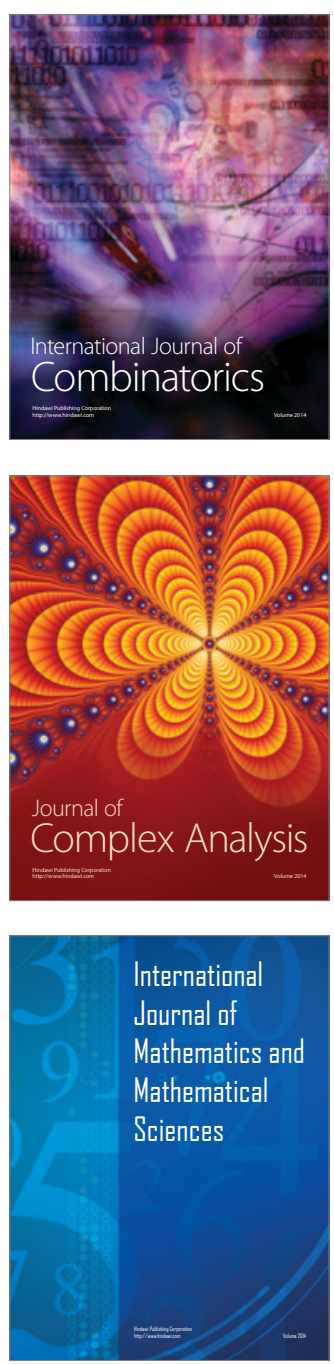
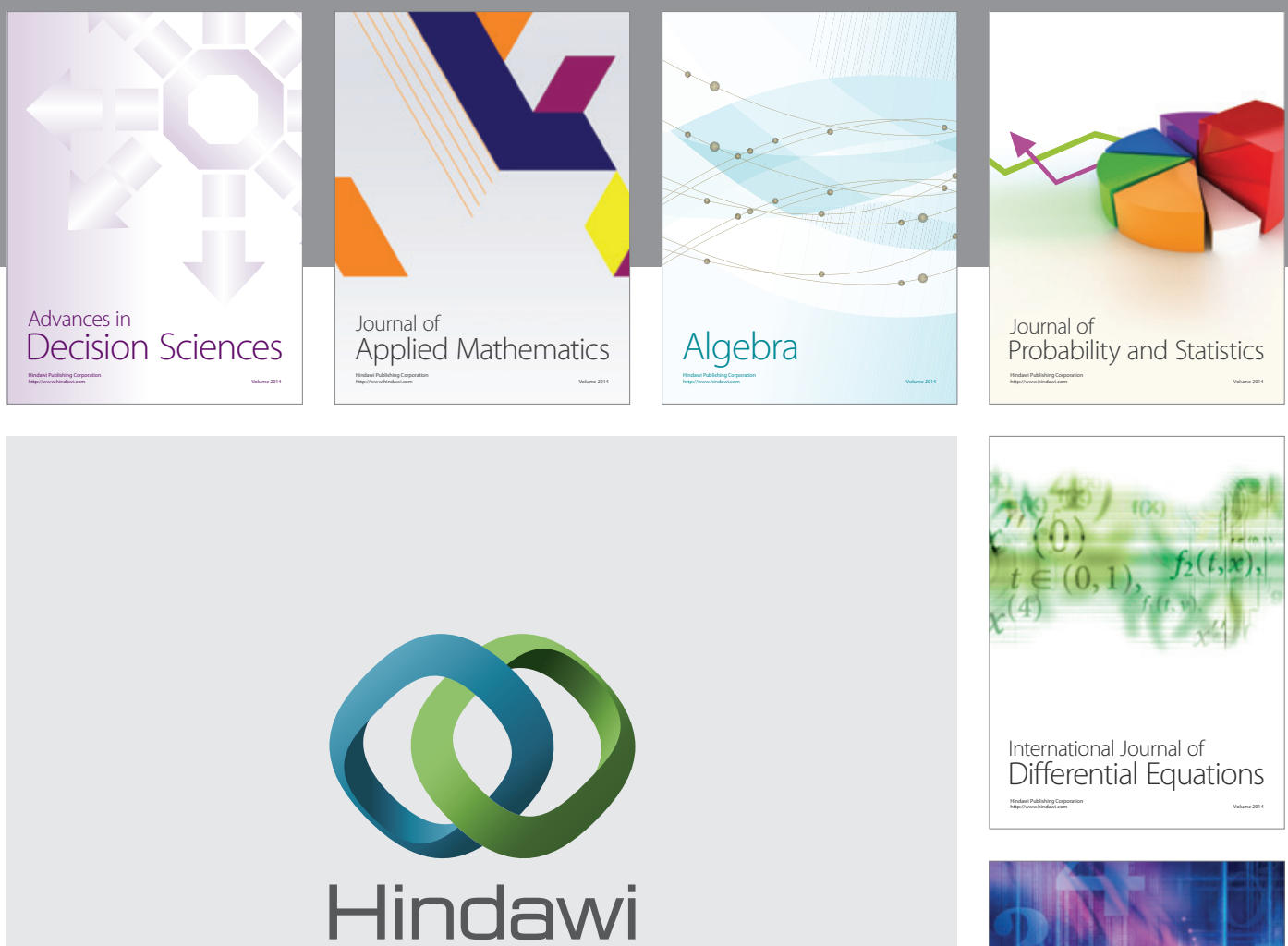

Submit your manuscripts at http://www.hindawi.com
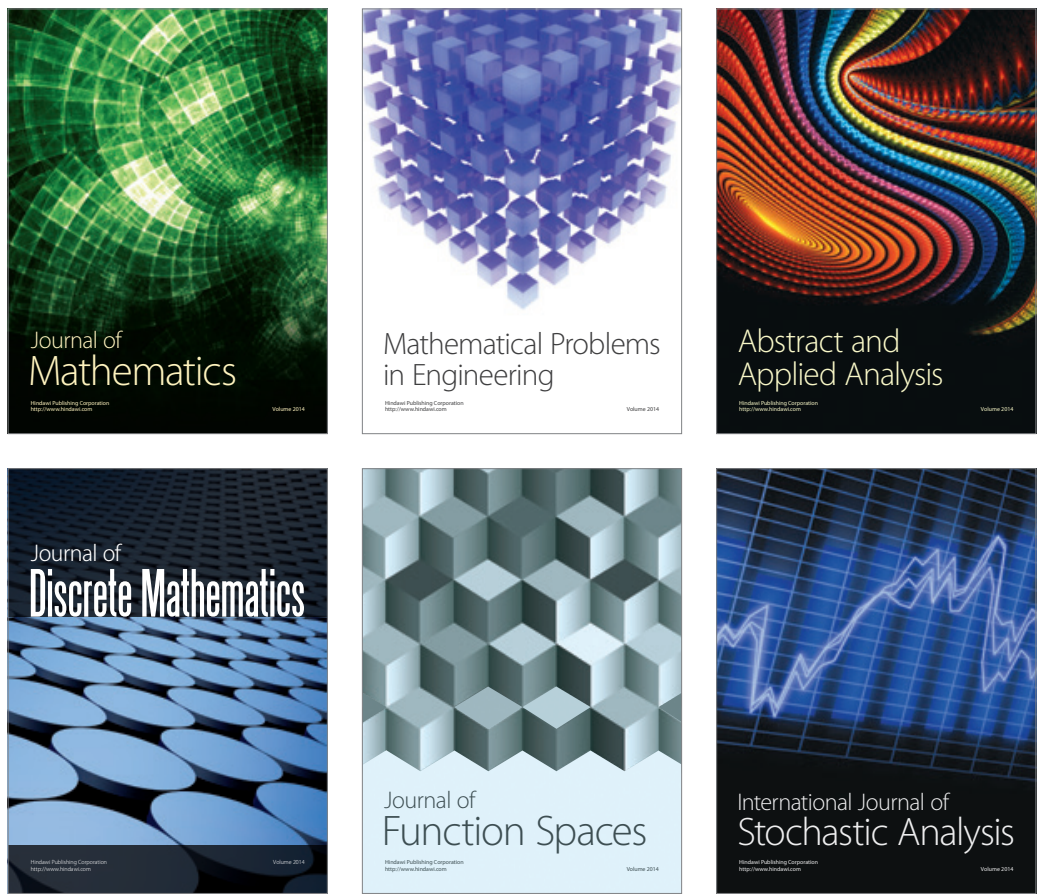

Journal of

Function Spaces

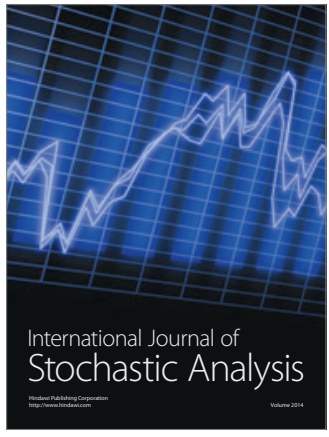

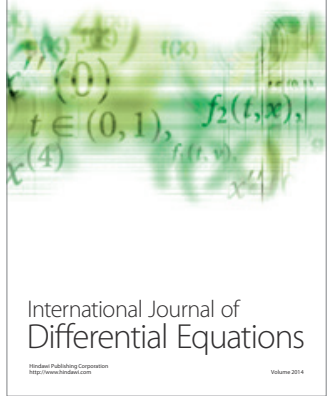
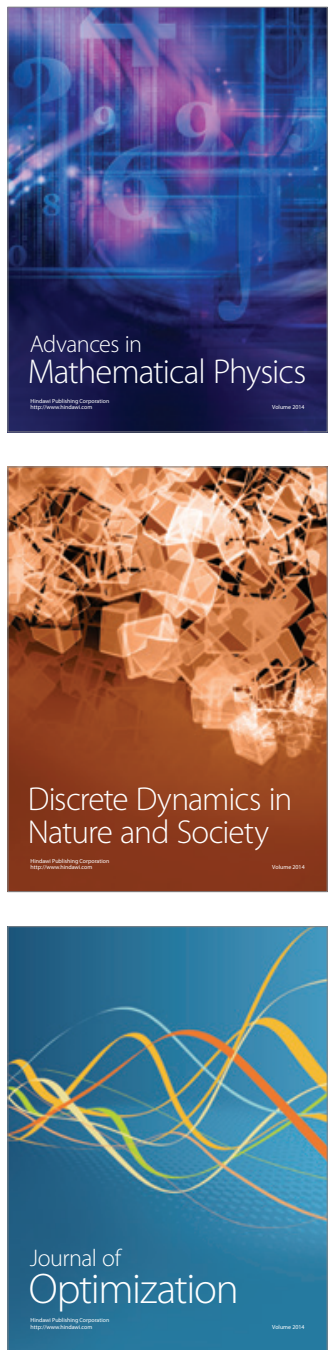